\title{
Administração pública gerencial e o protagonismo do empresariado na gestão da Educação: emergências e configurações
}

Management public administration and the entrepreneurship protagonism in Education management: emergencies and configurations

\section{Administración pública gerencial y protagonismo del empresariado en la gestión de la Educación: surgimientos y configuraciones}

\author{
Sonayra da Silva MedeIros MacÊdo ${ }^{1}$ \\ Maria Creusa de AraúJo Borges ${ }^{1} 1$ \\ ${ }^{1}$ Universidade Federal da Paraíba (UFPB), Campina Grande, PB, Brasil.
}

\begin{abstract}
RESUMO
O artigo examina o gerencialismo na gestão da educação pública, considerando a proposta de reforma administrativa, no Brasil, a partir de 1995. Busca-se, problematizar, a partir de estudo bibliográfico e de natureza conceitual, a emergência do modelo gerencial e do protagonismo do empresariado na gestão pública da educação, acrescentando dados de pesquisas realizadas em escolas públicas municipais. Parte-se do pressuposto que a concepção gerencial se intensifica com a regulamentação conferida pela Lei da Parceria Público-Privada, em 2004, e com a atuação do Terceiro Setor, o qual impõe novas configurações à gestão educacional pública brasileira. A pesquisa ressalta que a intervenção do empresariado na formulação de políticas educacionais impacta a gestão democrática da educação e da escola pública, uma vez que se consolida uma agenda em que a reforma administrativa e o setor privado ganham centralidade na direção de uma maior eficiência e produtividade, de controle dos gastos públicos, da responsabilização por resultados e da educação como um serviço.
\end{abstract}

Palavras-chave: Gestão da Educação. Modelo gerencial. Empresariado.

\begin{abstract}
The article analyzes the management of the public education, considering the purpose of administrative reform in Brazil, started in 1995. It's necessary to problematize, fron a bibliographic and conceptual study, of the emergence of managerial model and the protagonism of entrepreneurship in the public management of education, adding data from researches maked on municipal public schools. It is a presupposed that the managerial conception is intensified with the institution of the Public-Private Partnership Law in 2004, and the Third Sector, which imposes new configurations on the Brazilian public educational management. The research emphasizes that the intervention of business in the formulation of educational policies impacts the democratic management of education and public school, once an agenda is consolidated in which administrative reform and the private sector gain centrality towards greater efficiency and productivity, control of public spending, accountability for results, and education as a service.
\end{abstract}

Keywords: Education management. Management model. Business.

\section{RESUMEN}

El artículo revisa el gerencialismo en la gestión de la educación pública, considerando la propuesta de reforma administrativa en Brasil, a partir de 1995. Se busca, plantearse como problema, a partir de estudio bibliográfico y conceptual, el surgimiento del modelo gerencial y del protagonismo del empresariado en la gestión pública de la educación, añadiendo datos de investigaciónes realizadas en las escuelas públicas municipales. Se parte del supuesto que la concepción gerencial se intensifica con la normativa concedida por la ley de colaboración público-privada, en 2004, y con la actuación del Tercer Sector, que impone nuevas configuraciones a la gestión educacional pública brasileña. La investigación resalta que la intervención del empresariado en la elaboración de políticas educativas impacta la gestión democrática de la educación y de la escuela pública, puesto que se consolida un programa en el que la reforma administrativa y el sector privado adquieren papel central en la dirección de una mayor eficacia y productividad, del control de gasto público, de la responsabilización por resultados y de la educación como un servicio. Palabras clave: Gestión de la Educación. Modelo gerencial. Empresariado. 


\section{INTRODUÇÃo}

O artigo busca discutir a participação ativa do empresariado na educação brasileira, grupo que veio ganhando espaço de atuação desde a reforma administrativa de 1995 e intensificando suas ações nos anos 2000. Nesse sentido, observa-se, no cenário do século XXI, um aprofundamento da lógica gerencial, com aporte em normativa e no estabelecimento de parcerias, as quais inseriram novos atores na definição de políticas educacionais e consolidaram a participação do setor privado no espaço público.

Parte-se do pressuposto que a concepção gerencial de gestão da educação se intensifica no contexto da instituição da Lei da Parceria Público-Privada, a partir de 2004, no Brasil, e do alargamento da participação do Terceiro Setor, impondo novas configurações à gestão educacional.

Para aprofundar a análise da participação ativa da sociedade civil na nova relação com Estado, buscase, problematizar, com aporte em estudo bibliográfico, de natureza conceitual, e em legislação nacional, o protagonismo do empresariado na gestão pública da educação brasileira, tendo como um dos parâmetros a reforma administrativa desencadeada a partir da segunda metade da década de noventa do século XX.

O artigo é desenvolvido a partir de pesquisa do estado da arte sobre a concepção gerencial na administração pública. Primeiramente, com uma contextualização histórica do gerencialismo, sua emergência e configurações; na sequência, com identificação de marcos legais em contexto mundial e nacional que fortaleceram a lógica gerencial e favoreceram o protagonismo do empresariado nas políticas educacionais, acrescentando dados de pesquisa realizada em escolas públicas municipais, com aporte em Medeiros (2011, 2013), que trata da implementação de propostas de gestão por parte de institutos empresariais. Nesse cenário, examinase o alargamento da intervenção do empresariado na formulação de políticas de gestão na área educacional, o qual consideramos colidir com a perspectiva de gestão democrática da educação pública, princípio de natureza constitucional, inscrito na Constituição Federal de 1988, art. 206, inciso VI.

\section{O Modelo Gerencial na Administração Pública}

No contexto onde as referências neoliberais foram norte para a efetivação de reformas em vários países, foi possibilitada a emergência de um novo paradigma em administração pública, denominado gerencialista ou New Public Management. Segundo Costa (2010), as principais tendências desse paradigma são: descentralização administrativa e política; resolução de funções e autonomia ao mercado e à sociedade; flexibilização da gestão; ênfase na qualidade dos resultados; preocupação com a eficiência e redução de custos; busca de maior transparência no procedimento; aumento do controle social sobre a formulação, execução e avaliação das políticas.

A emergência do modelo gerencial na administração pública tem como fundamento três dimensões, problematizadas a partir da reformulação do Estado no contexto de crise dos anos setenta do século XX (ABRUCIO, 1997). A dimensão econômica, que era representada pelo keynesianismo, com ativa intervenção estatal na economia; a dimensão social, que compreendia o Welfare State, cujo objetivo principal era a produção de políticas públicas na área social; a administrativa, relacionada ao funcionamento interno do Estado, denominado modelo burocrático.

Na perspectiva de Abrucio (1997), não obstante a perspectiva gerencial ter alcançado centralidade nos governos neoliberais como o de Margaret Thatcher e Ronald Reagan, não se pode limitar essa concepção a esse cenário. Conforme alerta, a utilização do managerialism na administração pública se insere num debate que confere prioridade ao tema da reforma administrativa.

Abrucio (1997) analisa a introdução do modelo gerencial no setor público no contexto de reforma do Estado desde os anos 1970. Como uma resposta à crítica do modelo burocrático weberiano, defende-se o modelo gerencial, com ênfase no controle dos gastos públicos e na demanda pela melhor qualidade dos serviços nesse setor. Trata-se "[...] de reconstruir o setor público sob bases pós-burocráticas, bases estas que encontram no managerialism um de seus principais fundamentos" (ABRUCIO, 1997, p. 8).

No Brasil, essas mudanças foram efetivadas a partir da reforma na administração pública, em 1995, reforçando a crítica ao modelo burocrático e a necessidade de modernização da gestão, pautada na referência de qualidade do setor privado.

Os problemas de governabilidade do Estado contemporâneo foram resultantes de um Estado com menos recursos, mas também com menos poder. Portanto, para superação de tais problemas seria necessário que o aparato governamental fosse mais ágil e flexível. Nesse contexto, o managerialism substituiria o modelo weberiano, introduzindo a lógica da produtividade existente no setor privado (ABRUCIO, 1997).

O autor complementa que o avanço do modelo gerencial como referência para o setor público teve como reforço a defesa das reformas na administração pública, não somente pelo managerialism, mas pela ascensão de 
teorias críticas às burocracias estatais, como a Public Choice nos Estados Unidos e o ideário neoliberal de Hayek, principalmente na Grã-Bretanha.

A Teoria da Escolha Racional ou Public Choice (ou escolha pública), com a agregação de preferências individuais, parte do mesmo pressuposto de racionalidade econômica do interesse próprio, ou seja, da compreensão de que os indivíduos agem racionalmente no sentido de maximizar a utilidade de suas escolhas por bens e serviços (COSTA, 2010).

No contexto de crítica ao modelo burocrático, se intensifica um clima favorável aos ideais da iniciativa privada em detrimento da burocracia estatal, seja a partir de teorias seja pelo senso comum de que o setor privado possui o modelo ideal de gestão. $\mathrm{O}$ catalisador político para impor o modelo gerencial constitui a vitória dos governos neoliberais conservadores na Inglaterra (1979) e republicanos nos Estados Unidos (1980). Nas palavras de Abrucio,

[...] neste contexto de escassez de recursos públicos, enfraquecimento do poder estatal e de avanço de uma ideologia privatizante que o modelo gerencial se implantou no setor público. Coube aos conservadores ingleses e aos republicanos americanos a iniciativa nesse sentido, introduzindo, num primeiro momento, um modelo gerencial puro, em que prevalecia o ângulo meramente economicista ("cortar custos" como fim último) e o desconhecimento da especificidade do setor público (ABRUCIO, 1997, p. 11).

A NPM, New Public Management ou nova administração pública, a partir do final da década de 1970, assumia características de descentralização do aparelho do Estado, privatização das estatais, terceirização dos serviços públicos, regulação estatal das atividades públicas conduzidas pelo setor privado. Nesse sentido, programas semelhantes foram implantados em vários governos, no final do século XX, seguindo a lógica do aumento da eficiência, melhoria da qualidade dos serviços públicos, aumento da transparência e da accountability (COSTA, 2010).

$\mathrm{Na}$ reforma da administração pública brasileira de 1995, enfatizou-se a necessidade de aproximar o cidadão dos serviços públicos, defendendo, portanto, a descentralização como forma de inserir um caráter democrático na administração pública. Em contraposição ao discurso democrático, na prática, observou-se no decorrer dos anos pós reforma, uma ressignificação de princípios de gestão democrática, tais como: a participação, que assumiu caráter de execução de tarefas por parte dos envolvidos no setor público, bem como de ação voluntária; autonomia, no sentido de ampliar as formas de parcerias entre o setor público e o setor privado; descentralização, como responsabilização por resultados. Tais conceitos podem ser identificados nas políticas implementadas na área educacional, voltadas para atender as necessidades dos clientes dos serviços públicos.

O Estado foi considerado ineficiente e a administração pública deveria ser modernizada de modo a superar o modelo burocrático e incorporar novas formas de gestão, pautadas na flexibilidade, eficiência, eficácia e produtividade. Uma lógica neotecnicista ${ }^{1}$ que passou a influenciar as políticas públicas implementadas no Brasil, desde a reforma administrativa de 1995, e que se intensificou no século XXI, acentuando o protagonismo do setor privado nas políticas sociais, em especial, educacionais.

Em seus estudos sobre a reforma gerencial, Abrucio (1997) constata a existência de três tendências básicas: o modelo gerencial puro, o consumerism e o Public Service Orientation (PSO). O autor apresenta as mudanças ocorridas no managerialism, uma vez que, também, emergem respostas à crise do modelo burocrático weberiano, com a defesa da necessidade de um novo paradigma organizacional na administração pública.

Do debate do managerialism, surgem três visões da administração pública inglesa: o modelo gerencial puro, com objetivo da eficiência e produtividade, sendo o público-alvo os contribuintes; o Consumerism, com o objetivo da efetividade/qualidade, sendo o público-alvo os clientes/consumidores; e o Public Service Orientation, com objetivo da Accountabilility/equidade, e o foco nos cidadãos (ABRUCIO, 1997).

Abrucio (1997) explica que a discussão em torno do modelo gerencial ganhou novos rumos a partir da metade da década de 1980. O autor destaca que, basicamente, duas transformações foram operadas no gerencialismo puro. Uma priorizando os conceitos da flexibilidade, planejamento estratégico e qualidade. A outra transformação trata-se da adoção de serviços públicos voltados para os anseios dos clientes/consumidores, considerada a mais importante para remodelar o managerialism. Conforme complementa, "é neste ponto que o modelo gerencial traz à tona o aspecto público da administração pública, sem, no entanto, abandonar o conceito empresarial vinculado à eficiência e à busca da qualidade dos serviços" (ABRUCIO, 1997, p. 20).

$\mathrm{Na}$ década de oitenta, a administração da qualidade total (Total Quality Management - TQM), origina-se na iniciativa privada e, posteriormente, é introduzida no setor público. O aumento da concorrência e do nível de exigência

\footnotetext{
1 Termo utilizado por Dermeval Saviani (2010) para caracterizar o tecnicismo no contexto da década de 1990. Na referida década, a pedagogia tecnicista assume uma nova conotação, inserida num contexto de retenção de gastos e de investimentos públicos; e em defesa dos mecanismos de mercado, do apelo à iniciativa privada com intensificação das parcerias. Trata-se, então, conforme o autor, de um neotecnicismo.
} 
dos consumidores fez com que os empresários buscassem elevar a qualidade de seus produtos para sobreviver no mercado. No setor público, uma das principais mudanças no modelo gerencial esteve relacionada à qualidade total, que surgiu quando a administração pública também voltou sua atenção aos clientes/consumidores. Com essa ênfase às preferências do consumidor no espaço público, acredita-se que houve até mesmo uma mudança de paradigma (ABRUCIO, 1997).

Ainda nas reformulações concernentes a modelos de administração pública, o Public Service Orientation (PSO) foi criado buscando introduzir os conceitos de accountability e equidade na prestação de serviços públicos, como transparência, participação política, equidade e justiça, questões ausentes nas discussões iniciais sobre o modelo gerencial.

Abrucio (1997) explica que, não obstante o Public Service Orientation (PSO) faça fortes críticas ao modelo gerencial puro e ao consumerism, o mesmo não rompe com as ideias desenvolvidas no seio do Public Management. Isso porque foram incluídas discussões sobre eficiência, qualidade, avaliação de desempenho, flexibilidade gerencial, planejamento estratégico, porém com a tentativa de aperfeiçoá-las dentro de um contexto em que o referencial da esfera pública é o mais importante.

Pelas características do modelo gerencial, pode-se entender que a reforma da administração pública no Brasil, conduzidas por seus principais reformadores, o presidente à época, Fernando Henrique Cardoso, e o Ministro Bresser Pereira, condensaram, no Plano Diretor de Reforma do Aparelho do Estado (PDRAE, 1995), os princípios da New Public Management (NPM), já considerando as mudanças desde o modelo de gerencialismo puro.

Os princípios identificados com a nova administração pública buscavam fazer o governo funcionar melhor, custar menos e obter resultados. Conforme Costa (2010), a NPM também foi tributária das inovações introduzidas no campo da gestão empresarial, a partir da reestruturação produtiva caracterizada pelo pós-fordismo.

Como um documento-símbolo da nova discussão da administração pública americana, o qual aponta vários elementos das reformas administrativas realizadas posteriormente, em vários países, Abrucio (1997) e Costa (2010) destacam o livro Reinventando o governo de David Osborne e Ted Gaebler (1997), obra que se insere na perspectiva de gestão empreendedora e/ou inovadora dos governos, modelo que emergia nos Estados Unidos no início da década de 1990.

Osborne e Gaebler (1997) afirmam que o verdadeiro significado de empreendedor não são os empresários. O significado é mais amplo e implica que empreendedor emprega recursos de novas formas para maximizar a produtividade e eficiência. Nessa definição, se aplica igualmente aos setores públicos, privado e voluntário. Compreende-se, nesse sentido, que:

superintendentes e diretores escolares dinâmicos usam recursos de novas formas para maximizar a produtividade e eficiência das escolas. Da mesma forma, no modelo empreendedor defendido para o setor público as instituições do setor público usam seus recursos para aumentar eficiência e efetividade (OSBORNE \& GAEBLER, 1997, p.XVI).

Abrucio (1997) ressalta que essa obra se tornou uma das peças-chave do programa de governo do presidente Bill Clinton, mas que, também, podemos traçar um perfil das principais mudanças administrativas que afetaram o setor público em escala global.

Costa (2010), adotando uma perspectiva temporal, define as periodizações no processo de evolução do Estado brasileiro. Segundo ele, o período de 1808 a 1930 trata-se da construção do Estado nacional; de 1930 a 1945, do contexto da burocratização do Estado nacional; de 1945-1964, do nacional-desenvolvimentismo; de 1964 a 1989, da modernização autoritária; de 1990 a 2002, da era do gerencialismo.

Isso porque a segunda metade da década de 1990 constitui-se marco da reforma administrativa no Brasil, sendo a principal concepção de administração pública a contida no Plano Diretor de Reforma do Aparelho do Estado, documento-símbolo e orientador da reforma do aparelho estatal na perspectiva gerencial (BORGES, 2015), que promoveu mudanças na administração pública cujas continuidades e aperfeiçoamentos se fazem presentes. Com um discurso enfático de que a crise era do Estado, a reforma administrativa, a partir de 1995, foi considerada fundamental para a melhoria da qualidade da gestão pública. Defende-se, com isso, dentre outras bandeiras, a eficiência na gestão, novas formas de participação dos cidadãos enquanto usuários dos serviços públicos, a responsabilização, avaliação com ênfase nos resultados, a descentralização, flexibilidade.

Nessa perspectiva, o contexto da reforma administrativa brasileira é relevante no exame das mudanças subsequentes na administração pública, as quais se baseiam na modernização da gestão com a adoção do modelo gerencial inspirado na administração das empresas. Tais mudanças foram ampliadas a partir de eventos internacionais e nacionais em defesa de reformas na área educacional no final da década de 1990 e início dos anos 2000 .

Nesse quadro, se assiste à defesa do Estado empreendedor e da modernização do setor público com o aumento da accountability, fomento à participação da comunidade e do setor privado para solução de problemas sociais, aspectos, também, identificados nas mudanças 
ocorridas na administração pública brasileira no final do século XX e limiar do século XXI. Defende-se, portanto, uma gestão pública modernizada e pautada em parâmetros de qualidade das empresas, com incentivo à sociedade civil ativa e apelo ao voluntariado.

Costa (2010) esclarece que a nova gestão pública ou managerialism também pode aparecer como ideologia a serviço do mercado e da livre iniciativa. Nessa perspectiva, o pressuposto da racionalidade econômica, mais uma vez, define as expectativas de comportamento de todos os agentes públicos e privado, individuais e coletivos. $\mathrm{O}$ autor analisa que, nessa ótica, o Estado se concentra em funções regulatórias, uma vez que seu espaço de intervenção é reduzido e as políticas sociais de caráter compensatório têm sua execução delegada a terceiros.

Nesse contexto do gerencialismo, Costa (2010) ressalta que a eficiência passa a ser evidenciada como valor prioritário. Os cidadãos são considerados clientes; bens e serviços públicos são avaliados por critérios de mercado; organismos públicos passam a adotar métodos empresariais de gestão, intensificando a avaliação dos funcionários públicos por critérios de desempenho similares aos utilizados pelas empresas privadas.

No cenário brasileiro, a administração pública gerencial, consubstanciada no Plano Diretor (1995), emerge como resposta,

[...] de um lado, à expansão das funções econômicas e sociais do Estado, e, de outro, ao desenvolvimento tecnológico e à globalização da economia mundial, uma vez que ambos deixaram à mostra os problemas associados à adoção do modelo anterior. A eficiência da administração pública - a necessidade de reduzir custos e aumentar a qualidade dos serviços, tendo o cidadão como beneficiário torna-se então essencial. A reforma do aparelho do Estado passa a ser orientada predominantemente pelos valores da eficiência e qualidade na prestação de serviços públicos e pelo desenvolvimento de uma cultura gerencial nas organizações (BRASIL, 1995, p.15-16).

Nessa perspectiva, na Reforma do Aparelho do Estado, proposta pelo Pano Diretor, em 1995, compreende-se que:

O paradigma gerencial contemporâneo, fundamentado nos princípios da confiança e da descentralização da decisão, exige formas flexíveis de gestão, horizontalização de estruturas, descentralização de funções, incentivos à criatividade. Contrapõe-se à ideologia do formalismo e do rigor técnico da burocracia tradicional. À avaliação sistemática, à recompensa pelo desempenho, e à capacitação permanente, que já eram características da boa administração burocrática, acrescentam-se os princípios da orientação para o cidadão-cliente, do controle por resultados, e da competição administrada (BRASIL, 1995, p. 17).
$\mathrm{Na}$ defesa de mudanças do neoliberalismo ortodoxo, estratégias são buscadas para obter o consenso da sociedade em prol de um novo projeto de sociabilidade, mas que não significa uma ruptura com o ideário neoliberal. De acordo com Sousa, Melo e Melo (2015), organismos internacionais como o Fundo Monetário Internacional (FMI) e Banco Mundial, em seus documentos e propostas divulgadas no Brasil, passaram a mudar o discurso em favor do novo projeto, propondo ações de alívio à pobreza e de desenvolvimento sustentável, inclusive defendendo políticas compensatórias para minimizar desigualdades sociais. Nesse contexto, passaram a clamar por um novo papel do Estado na dinâmica do capitalismo contemporâneo, na perspectiva de um Estado estritamente necessário.

Considerando as análises de Osborne e Gaebler (1997), as quais apontam o espírito empreendedor como estratégia eficiente para transformar o setor púbico, o governo deve ser catalisador e, para isso, precisa "navegar em vez de remar". Compreende-se que a ação de remar deve ser atribuída a empresários, organizações do terceiro setor, ONGs, comunidade em geral. Em outras palavras, os autores defendem o pensamento de governos empreendedores da década de 1990, os quais entendem, por exemplo, que o objetivo principal do governo do Estado é ser o catalisador na assistência às comunidades, dando a estas o poder de resolver seus próprios problemas. Segundo os autores destacam, esse pensamento traz a aprendizagem de que o barco do Estado pode navegar mais eficazmente se forem os outros a remar, e não só o governo. Para eles, a partir de suas pesquisas, os governos que marcaram melhor o rumo da sociedade remando menos eram claramente governos mais fortes.

$\mathrm{Na}$ nova relação entre Estado e sociedade civil, inserida no projeto de sociabilidade do Neoliberalismo de Terceira Via no Brasil2, os governos intensificam o chamamento à comunidade e a atores da sociedade civil no sentido de motivar a mobilização de todos para participação na implementação das políticas sociais. Nesse processo, os empresários vêm cumprindo papel consideravelmente ativo, não apenas nas discussões sobre tais políticas, mas definindo os rumos, especialmente, da gestão da educação pública brasileira.

As propostas do empresariado no âmbito da gestão da escola pública indicam a intensificação do modelo de administração pública gerencial, defendido a partir da década de 1990, no Brasil. Nesse sentido, parte-se do pressuposto que o protagonismo do empresariado resulta de um processo efetivo de reconfiguração da sociedade civil na sua relação com o Estado ao longo das décadas. Tal

\footnotetext{
2 Estudos sobre o Neoliberalismo de Terceira Via e a nova Pedagogia da Hegemonia (NEVES, 2005; MARTINS, 2009)
} 
reconfiguração vem promovendo uma maior articulação do setor empresarial na operacionalização das políticas públicas, ampliando o poder de atuação das fundações e dos institutos de grandes empresas, que em regime de parceria com o setor público, assumem o caráter da responsabilidade social e definem propostas e programas para a melhoria da qualidade da educação básica no Brasil. Nesse cenário, cumprindo a agenda de um novo projeto de sociabilidade, o empresariado se constitui como um ator político indispensável à consolidação da perspectiva gerencialista de gestão pública da educação, nos termos da reforma administrativa e da lógica da parceria públicaprivada.

\section{Protagonismo do Empresariado Nas Políticas Educacionais: IMPACTOS NA GESTÃ̃O}

De acordo com a perspectiva da reforma do Estado, as variações ocorridas em relação às estratégias para implementação das políticas sociais, na ótica da Terceira Via, também exigem um novo posicionamento do empresariado. O programa aponta, segundo Martins (2009), para a renovação política da classe empresarial, sendo necessário que esta assuma um novo papel e conduta na sociedade civil, referenciada no postulado da responsabilidade social.

A responsabilidade social das empresas também foi motivada pelo Pacto Global da Organização das Nações Unidas (ONU), iniciativa criada em 1999, no Fórum Econômico Mundial de Davos, na Suíça, com o objetivo de incentivar a ação de pessoas e empresas em várias áreas de responsabilidade social. Em 2011, oito mil instituições de 135 países, das quais mil empresas, faziam parte do Pacto Global da ONU. Segundo o diretor executivo do Pacto, Georg Kell, o aumento de investimentos de empresas em ações estratégicas de responsabilidade social se deve à busca pela construção de uma nova forma de conduzir os negócios (PORTAL BRASIL, 2011).

Essa nova forma de condução dos negócios aponta para o protagonismo do empresariado, que vai criar seus institutos e fundações para atuar legalmente junto ao setor público, por meio das parcerias, ampliando os espaços de atuação e consolidando novas formas de implementar políticas públicas. Assim, não se trata somente de o governo assumir a agenda do empresariado, mas deste grupo definir a agenda do governo. O empresariado nacional, nesse contexto, vem fazendo com que, cada vez mais, o setor público "vista a camisa" das empresas que se estabelecem como responsáveis socialmente, disseminando ideias em favor da ação dos empresários, inculcando a lógica da excelência, dos projetos exitosos, dos resultados e da qualidade total. Ou seja, o setor privado é evidenciado como o mais capaz de promover melhorias no espaço público, sem o qual as políticas públicas estariam destinadas ao fracasso.

A atuação do empresariado na definição das políticas educacionais recebe influência de debates em nível mundial. Nesse âmbito, são destacadas as principais influências internacionais, buscando compreender essas repercussões e como o empresariado, no Brasil, ganha centralidade, não apenas nas discussões das políticas implementadas no setor público, mas na condição de participantes ativos na definição e monitoramento dessas políticas, especialmente, as direcionadas à Educação Básica.

O movimento dos empresários e sua participação ativa na gestão da educação brasileira ganham reforço com a construção do marco legal das parcerias públicoprivadas, em 2004, com sua revisão em 2016. Assim, são legalizadas as parcerias entre o setor público e privado no trato das questões educacionais.

Algumas medidas, no Brasil, consubstanciadas em marcos jurídicos e regulatórios, legitimaram a participação dos empresários e do Terceiro Setor. Partindo da ideiaforça sobre a falência do Estado, as novas medidas para a governabilidade necessitam da participação do setor privado. Este passa a atuar nas questões sociais por intermédio do Terceiro Setor, constituído por organizações sob o regime da propriedade privada, sem fins lucrativos, mas que existem para atender às necessidades públicas ou sociais. Por outro lado, conforme compreensão de Osborne e Gaebler (1997), no Terceiro Setor são incluídas também as instituições com o objetivo de lucro que existem para atender a demandas sociais ou públicas, como bancos de desenvolvimento.

A influência do setor privado nas discussões relacionadas à área de educação brasileira já foi uma constante em período anterior a década de 1990. Cabe destacar que o texto constitucional de 1967 também "deu margem ao setor privado de beneficiar-se de recursos públicos para manutenção e funcionamento" (BRASIL/ IPEA, 2009, p. 18). No processo da constituinte de 19871988 , no contexto dos embates no campo educacional, as entidades do setor privado continuaram buscando ganhar espaço de atuação no setor público.

Em contexto mais recente, pode-se destacar os programas de privatização e de publicização no Plano Diretor, um marco de 1995, que também evidencia a participação do setor privado na modernização da administração pública, com incentivo às parcerias. Nessa perspectiva, destaca-se também a divisão da administração pública brasileira em setores ou núcleos. Esta reforma, de acordo com Borges (2015, p. 968) "é feita segundo a lógica da relação custo-benefício, na busca de qualidade, com menor custo, na prestação dos serviços públicos". 
Estabelece-se, ainda, nesse cenário de reformas, no final do século XX, a Lei no 9.637, de 15 de maio de 1998, que dispõe sobre a qualificação de entidades como organizações sociais e a criação do Programa Nacional de Publicização; a Lei no 9.790, de 23 de março de 1999, a qual dispõe sobre a qualificação de pessoas jurídicas de direito privado, sem fins lucrativos, como Organizações da Sociedade Civil de Interesse Público.

A parceria entre o setor público e privado, no Brasil, foi legalmente estabelecida no governo Luís Inácio Lula da Silva pela Lei Federal da Parceria Público-Privada, no 11.079, de 30 de dezembro de 2004, que institui "normas gerais para licitação e contratação de parceria públicoprivada no âmbito dos Poderes da União, dos Estados, do Distrito Federal e dos Municípios" (BRASIL, 2004, p. 1).

Há, nesse sentido, uma abertura para as parcerias entre o setor público e o privado, estabelecida em lei, para o compartilhamento de atividades, via contratos e contraprestações. Segundo Borges (2015):

A realização de contratos de parceria público-privada é norteada por algumas diretrizes, como a questão da indelegabilidade. Recupera-se, dessa forma, a discussão proposta no Plano Diretor da Reforma do Aparelho do Estado (1995). Assim, quando a atividade se constitui em serviço não exclusivo, justifica-se a realização da parceria público-privada. Contrariamente, quando se constitui em atividade exclusiva do Estado, portanto, como um não-serviço, a parceria em tela não é justificada (BORGES, 2015, p. 971).

A lei da parceria público-privada, instituída em 2004, ampliou a intervenção do empresariado na educação brasileira e possibilitou chegarem às escolas públicas propostas gerenciais, mais especificamente, elaboradas por especialistas de vários institutos ou fundações empresariais com foco na responsabilidade social, dentre os quais podemos destacar o Instituto Camargo Correa e o Instituto Ayrton Senna, atuantes na área educacional. Na rede Municipal de Campina Grande, na Paraíba, e em vários Municípios do Brasil, também existem intervenções do empresariado na Educação, dentre outras, a Fundação Lemann, atualmente com a implementação do Programa Gestão para a Aprendizagem, desenvolvido em parceria com as prefeituras e a consultoria Elos Educacional.

ACampanha Nacional pelo Direito à Educação também cumpriu papel estratégico no sentido de mobilização de atores para intervenção na área educacional. Pretendeu-se "[...] promover mobilizações com redes de todo o mundo para cobrar dos respectivos governos o cumprimento das metas do Marco de Ação da Educação Para Todos, acordo assinado em 2000, em Dakar (Senegal)" (CAMPANHA NACIONAL PELO DIREITO À EDUCAÇÃO, 2016).
No Brasil, a Campanha Nacional pelo Direito à Educação, vinculada à Campanha Global pela Educação, é responsável pela organização da Semana de Ação Mundial, desde 2001. Surgida em 1999, a campanha teve como objetivo "somar diferentes forças políticas, priorizando ações de mobilização, pressão política e comunicação social, em favor da defesa e promoção dos direitos educacionais" (CAMPANHA NACIONAL PELO DIREITO À EDUCAÇÃO, 2017).

Compatível com essa lógica de mobilização do empresariado e atuação junto ao governo na área educacional, a Semana de Ação Mundial (SAM), ocorrida em 23 a 27 de abril de 2007, por exemplo, buscou envolver redes, organizações e campanhas de mais de 100 países no movimento global pela educação, colocandose como evento que objetiva pressionar governos e lideranças em melhoria de condições da escola pública. Conforme no sítio da Campanha Nacional pelo Direito à Educação (2016), a Semana de Ação Mundial, a partir de 2015, no Brasil, passou a ter também como temática o monitoramento do cumprimento das metas e estratégias do Plano Nacional de Educação 2014-2024.

A mobilização de parceiros empresariais também pode ser identificada no posicionamento da Organização das Nações Unidas no Brasil, a ONU, a qual destaca que os critérios utilizados por suas agências, seus programas e fundos para escolher seus parceiros são baseados em princípios gerais da Organização, acrescidos de outros mais específicos relacionados à missão e mandato de cada agência. Alguns princípios elencados, nesse sentido, defendem que:

- Parceiros empresariais devem demonstrar cidadania responsável, apoiando as causas e valores da ONU presentes na Carta das Nações Unidas e em outras convenções e tratados relevantes;

- Dentro de sua esfera de influência, empresas privadas devem demonstrar compromisso em alcançar e respeitar os princípios estabelecidos no Pacto Global e traduzi-los em práticas coorporativas operacionais (ONUBR, 2016).

Destaca-se, no processo de mobilização do empresariado na Educação brasileira, o Movimento Todos pela Educação. Fundado em 2006, identifica-se como um "movimento da sociedade brasileira que tem como missão engajar o poder público e a sociedade brasileira no compromisso pela efetivação do direito das crianças e jovens a uma Educação Básica de qualidade" (TODOS PELA EDUCAÇÃO, 2017). Esse Movimento pela educação tem vários parceiros e mantenedores, dentre eles institutos e fundações empresariais. Como alguns exemplos dessas parcerias destacamos a Fundação Bradesco, Itaú Social, Gerdau, Instituto Ayrton Senna, 
Banco Interamericano de Desenvolvimento (BID), Rede Globo, Vivo, Fundação Roberto Marinho.

No Plano de Desenvolvimento da Educação, em 2007, o governo brasileiro assume a agenda dos empresários, especialmente com o Plano de Metas Compromisso Todos Pela Educação, Decreto no 6.094, de 24 de abril de 2007, que dentre as metas estabelecidas, destaca-se a XXVIII diretriz, que reforça a mobilização de diversos atores para atuação na Educação. Conforme o plano, determina-se:

organizar um comitê local do Compromisso, com representantes das associações de empresários, trabalhadores, sociedade civil, Ministério Público, Conselho Tutelar e dirigentes do sistema educacional público, encarregado da mobilização da sociedade e do acompanhamento das metas de evolução do IDEB (BRASIL, 2007).

Quanto à adesão ao Compromisso por Estados, Municípios e Distrito Federal, no artigo sexto do compromisso (2007), destaca-se que será instituído o Comitê Nacional do Compromisso Todos pela Educação, incumbido de colaborar com a formulação de estratégias de mobilização social pela melhoria da qualidade da educação básica, que subsidiarão a atuação dos agentes públicos e privados.

$\mathrm{Na}$ sequência, no artigo sétimo do plano, destacase quais atores podem colaborar com o Compromisso, em caráter voluntário: outros entes, públicos e privados, tais como organizações sindicais e da sociedade civil, fundações, entidades de classe empresariais, igrejas e entidades confessionais, famílias, pessoas físicas e jurídicas que se mobilizem para a melhoria da qualidade da educação básica (BRASIL, 2007).

As perspectivas da mobilização social e da atuação empresarial estão presentes no Plano de Metas Compromisso Todos pela Educação, respaldadas, assim, por marco jurídico e regulatório, que possibilita o alargamento da participação de atores do setor privado para intervir no setor público, na área social, em especial, educacional.

Nesse cenário, também são identificados, no sítio do Ministério da Educação (MEC), os atuais parceiros do Plano de Mobilização Social pela Educação ${ }^{3}$, que foi lançado em 2008 para mobilizar todos para melhoria da qualidade da educação. Além de igrejas cristãs e outras

\footnotetext{
${ }^{3}$ Lançado em 2008, pelo MEC, o Plano de Mobilização Social pela Educação "é o chamado do Ministério à sociedade para o trabalho de mobilização das famílias e comunidades pela melhoria da qualidade da educação e pela garantia do direito de aprender a todos os brasileiros. O Plano oferece orientação e incentivo a lideranças sociais, gestores da educação pública, profissionais da educação e representantes de segmentos organizados, entre outros, para a realização de ações norteadas pelo diálogo com as famílias a respeito da importância da educação e do acompanhamento, por parte dos pais, na vida escolar dos filhos" (BRASIL/MEC, 2016).
}

denominações religiosas, fazem parte dessa parceria as empresas: ArcelorMittal, Bradesco, CCPR - Consórcio Camargo Corrêa Promon; Camargo Corrêa; Grupo Santander, Natura, Vale, Votorantim, Itaú, Walmart, Planeta Educação. Estes são, apenas, uma parcela dos grupos do empresariado que atuam na educação brasileira.

Nesse contexto do início do século XXI, é evidente a inserção do empresariado para intervir na Educação, por meio de parcerias, uma vez que encontra respaldo legal para as suas ações nas políticas implementadas pelo governo.

No tocante à repercussão dessas intervenções na escola pública, com propostas gerenciais, destaca-se a implementação do Sistema de Gestão Integrado (SGI) ${ }^{4}$ em escolas municipais de Campina Grande, na Paraíba, a partir de pesquisas realizadas por Medeiros $(2011,2013)$. Nesse processo, identificou-se uma proposta de gestão com fortes características empresariais, a começar pelos próprios termos utilizados no documento, próprios de empresas, tais como: test drive do professor, liderança, satisfação do cliente, serviços educacionais.

No desenvolvimento dessa pesquisa, a partir de dados coletados com gestoras e professores/as, foram observadas dificuldades no processo de implementação, uma vez que apenas gestores e supervisores participaram da formação promovida pelo Instituto Alpargatas para o desenvolvimento do projeto na escola. O documento do SGI também era restrito a estes profissionais, denominados, pelo Sistema, de equipe de liderança da escola. Além disso, o SGI configurou-se em extenso documento prescritivo que continha passos a serem seguidos por um pequeno grupo de líderes, no sentido de convencimento dos chamados "disciplinados" ${ }^{\text {da }}$ organização para execução da proposta.

A implementação do SGI na escola pública é um nítido exemplo de que o empresariado também define a agenda governamental de efetivação das políticas públicas e, consequentemente, os rumos da educação no Brasil, bem como as formas de intervenção na escola pública, conforme pode-se conferir em pesquisas da autora supracitada.

As principais dimensões na implementação do SGI na escola pública, as quais caracterizam o modelo gerencial, destacadas por Medeiros (2013), a partir da análise documental e da pesquisa nas escolas da rede municipal, foram: a ênfase no alto desempenho do aluno; poder centralizado no gestor; empoderamento (empowerment);

\footnotetext{
${ }^{4}$ Sistema de Gestão desenvolvido pela Fundação Pitágoras e adotado pelo Programa Escola Ideal, do Instituto Camargo Corrêa. Implementado nas escolas municipais de Campina Grande em parceria com o Instituto Alpargatas.

5 Termo utilizado no documento do SGI para se referir aos profissionais da escola pública.
} 
participação com ênfase na execução de tarefas; qualidade da escola diretamente relacionada ao desempenho do aluno; preocupação com o cidadão/cliente; necessidade de aumento da produtividade e eficiência por parte de todos que atuam na escola; professor limitado a sua sala de aula, com ações centradas na elaboração de missões, metas, na organização de dados numéricos e exposição de gráficos; estratégias de accountability ou responsabilização pelos resultados; construção, pelo gestor, de uma capacidade operacional, incluindo proatividade, agilidade e flexibilidade.

Nessa conjuntura, é importante examinar e problematizar as implicações do protagonismo do empresariado na gestão educacional, explicitando os termos da parceria com o setor público e sua fundamentação jurídica em cenários de reformulação do Estado na perspectiva gerencial.

\section{CONSIDERAÇões Finais}

O modelo gerencial apresenta princípios democráticos em sua proposta, tais como conceitos de participação, descentralização, autonomia, mas com conteúdos ressignificados quanto à operacionalização nos planos de gestão educacional. Com ênfase nos parâmetros de qualidade das empresas, de eficiência e da gestão para resultados, busca-se transpor para o espaço público educacional uma dinâmica que se contrapõe à perspectiva democrática nos termos da Constituição Federal de 1988, art. 206, VI, e da Lei de Diretrizes e Bases da Educação Nacional, art. 3으, VIII.

$\mathrm{O}$ exame da emergência do modelo gerencial na administração pública indica sua construção e consolidação em contextos de reformulação do Estado em cenários de crise. Nesses contextos, consolida-se uma agenda em que a reforma administrativa e as parcerias público-privadas ganham centralidade na direção de uma maior eficiência e produtividade, controle dos gastos públicos, maximização da relação custo-benefício, responsabilização pelos resultados e educação como um serviço, em detrimento da concepção de educação como um direito fundamental (BORGES, 2015).

Nesse âmbito, no processo de reformulação do Estado, emerge um protagonismo do empresariado na gestão educacional, com base na assunção de uma perspectiva gerencial. Destaca-se, com aporte na operacionalização de um marco jurídico propício e incentivador das parcerias público-privadas, a atuação de grupos empresariais na formulação de políticas educativas com repercussões na gestão escolar.

Observa-se que, nesse cenário, os projetos dos atuais reformadores educacionais, mesmo impactando a gestão democrática, são evidenciados pelos governos enquanto referências em qualidade educacional, inovadores e exitosos, aqueles que conseguem eficazmente promover melhorias necessárias no espaço público.

A partir de tal compreensão, é justificado o protagonismo do empresariado junto ao governo. Confere-se respaldo legal para a sua atuação na definição de políticas públicas para educação, sobretudo na gestão educacional, possibilitando a intervenção na escola pública ena formação dos profissionais da área educacional, determinando os rumos para o setor público. Questões que desafiam os defensores da gestão democrática da escola pública a pensar novas estratégias que se contraponham à lógica gerencial e que resgatem a perspectiva emancipatória de uma educação pública de qualidade no contexto prático de efetivação das políticas educacionais.

Nessa perspectiva, coloca-se como necessário o exame desse alargamento do protagonismo do empresariado, com exigência de maior transparência na execução das parcerias público-privadas. Assim, a análise dos termos dessas parcerias torna-se uma problemática relevante, no sentido de garantir um maior controle social sobre elas, na direção da efetivação do direito à educação.

O debate sobre a atuação do empresariado na Educação pública brasileira pode ser aprofundado a partir de estudos sobre as propostas educacionais de institutos e fundações empresariais que atuam junto ao governo, e com investigações nas redes públicas de ensino para identificação e análise de projetos pensados pelo setor privado e implementados nas escolas públicas sob a lógica gerencial.

Destarte, consideramos relevante o aprofundamento das pesquisas empíricas nesse campo, no sentido de investigar a efetividade da gestão democrática; as possíveis implicações do gerencialismo, bem como das propostas empresariais na gestão das escolas públicas; sobretudo, as repercussões no trabalho docente, nos planos de gestão, na gestão dos recursos públicos e na promoção de modelos de gestão mais transparentes, de forma a promover o acompanhamento e o controle social.

\section{REFERÊNCIAS}

ABRUCIO, Fernando Luiz. O impacto do modelo gerencial na Administração Pública: um breve estudo sobre a experiência internacional recente. Cadernos ENAP, Brasília, DF, n. 10, p. 1-50, 1997.

BORGES, Maria Creusa de Araújo. Regulação da educação superior brasileira: a Lei de Inovação Tecnológica e da Parceria Público-Privada. Revista Educação e Pesquisa, São Paulo, 41, n. 4, p. 961-973, out./dez. 2015. Disponível em: http://www.scielo.br/pdf/ep/v41n4/1517-9702-ep-41-4-0961. pdf. Acesso em: 12 abr. 2017. https://doi.org/10.1590/S15179702201512130955 
BRASIL. Constituição (1988). Constituição da República Federativa do Brasil. Brasília, DF: Senado Federal: Centro Gráfico, 1988. Disponível em: http://www.planalto. gov.br/ccivil_03/constituicao/constituicao.htm. Acesso em: 04 maio 2018.

BRASIL. Lei no 9.394, de 20 de dezembro de 1996. Estabelece as diretrizes e bases da educação nacional. Brasília, DF: 1996. Disponível em: http://www.planalto. gov.br/ccivil_03/leis/19394.htm. Acesso em: 04 jun. 2018.

BRASIL. Presidência da República. Câmara da Reforma do Estado. Plano diretor da reforma do aparelho do Estado. Brasília, DF: 1995. 68 p. Disponível em: http:// www.bresserpereira.org.br/documents/mare/planodiretor/ planodiretor.pdf. Acesso em: 15 mar. 2017.

BRASIL. Lei no 9.637, de 15 de maio de 1998. Lei das Organizações Sociais. Dispõe sobre a qualificação de entidades como organizações sociais [...]. Brasília, DF: 1998. Disponível em: http://www.planalto.gov.br/ccivil_03/leis/ L9637.htm. Acesso em: 04 abr. 2017.

BRASIL. Lei no 9.790, de 23 de março de 1999. Lei das OSCIP. Dispõe sobre a qualificação de pessoas jurídicas de direito privado, sem fins lucrativos, como Organizações da Sociedade Civil de Interesse Público. Brasília, DF: 1999. Disponível em: http://www.planalto.gov.br/ccivil 03/leis/ L9790.htm. Acesso em: 18 maio 2017.

BRASIL. Lei no 11.079, de 30 de dezembro de 2004. Lei Parceria Público-Privada. Institui normas gerais para licitação e contratação de parceria público privada no âmbito da administração pública. Brasília, 2004. Disponível em: http://www.planalto.gov.br/ccivil_03/_ato2004-2006/2004/ lei/111079.htm. Acesso em: 12 maio 2017.

BRASIL. Decreto no 6.094, de 24 de abril de 2007. Dispõe sobre a implementação do Plano de Metas Compromisso Todos pela Educação, pela União Federal, em regime de colaboração com Municípios, Distrito Federal e Estados [...]. Brasília, DF, 2007. Disponível em: http://www.planalto.gov. br/ccivil_03/ato2007-2010/2007/decreto/d6094.htm. Acesso em: 10 fev. 2018.

BRASIL. IPEA. Vinte anos da constituição federal de 1988: avanços e desafios na educação brasileira. In: BRASIL. IPEA. Políticas Sociais: acompanhamento e análise - 20 anos da Constituição Federal. 17. Vol. Brasília: Diretoria de Estudos e Políticas Sociais, 2009. p. 17-81.

\section{BRASIL. MEC. Plano de Mobilização Social pela} Educação. 2016. Brasília, DF: Disponível em: http://mse. mec.gov.br/index.php. Acesso em: 9 out. 2016.

CAMPANHA NACIONAL PELO DIREITO À EDUCAÇÃO. Quem somos. 2017. Disponível em: http://campanha.org.br/ quem-somos/a-campanha/. Acesso em: 12 abr. de 2017.
CAMPANHA NACIONAL PELO DIREITO À EDUCAÇÃO. Semana de Ação Mundial. 2016. Disponível em: http:// campanha.org.br/semana-de-acao-mundial/. Acesso em out. 2016.

COSTA, Frederico Lustosa da. Reforma do Estado e contexto brasileiro: crítica do paradigma gerencialista. Rio de Janeiro: Editora FGV, 2010.

MARTINS, André Silva. O Neoliberalismo da Terceira Via: uma proposta para educar a sociabilidade. In: MARTINS, André Silva. A direita para o social: a educação da sociabilidade no Brasil contemporâneo. Juiz de Fora: UFJF, 2009. p. 59-110.

MEDEIROS, Sonayra da Silva. O gerencialismo em escolas públicas municipais de Campina Grande/PB: análise do Sistema de Gestão Integrado (SGI) e reflexões sobre a gestão democrática. 2011. 84 f. Monografia (Especialização em Políticas e Gestão da Educação Básica) - Unidade Acadêmica de Educação, Universidade Federal de Campina Grande/PB, Campina Grande, 2011.

MEDEIROS, Sonayra da Silva. O gerencialismo na educação pública: a implementação do Sistema da Gestão Integrado (SGI) na rede municipal de Campina Grande-PB. 2013. 152 f. Dissertação (Mestrado em Educação) - Programa de Pós-graduação em Educação, Universidade Federal da Paraíba, João Pessoa, 2013.

MELO, Adriana A. Sales; SOUZA, Camila Azevedo; MELO, Marcelo Paula. In: MARTINS, André; NEVES, Lúcia Maria Wanderley (org.). MELO, Adriana Almeida Sales et al. Educação básica: uma tragédia anunciada? São Paulo: Xamã, 2015.

NEVES, Lúcia Maria Wanderley. A sociedade civil como espaço estratégico de difusão da nova pedagogia da hegemonia. In: NEVES, Lúcia Maria Wanderley (org.). A nova pedagogia da hegemonia: estratégias do capital para educar o consenso. São Paulo: Xamã, 2005.

ONUBR. A ONU e as empresas. 2016. Disponível em: https://nacoesunidas.org/acao/empresas/. Acesso em: 16 nov. 2016.

OSBORNE, David; GAEBLER, Ted. Reinventando o governo: como o espírito empreendedor está transformando o setor público. 9. ed. Brasília: MH Comunicações, 1997.

PORTAL BRASIL, 2011. Crise aumentou responsabilidade social das empresas, mas diminuiu filantropia por parte de indivíduos, diz ONU. Disponível em: http://www.brasil. gov.br/governo/2011/10/crise-aumentou-responsabilidadesocial-das-empresas-mas-diminuiu-filantropia-por-parte-deindividuos-diz-onu. Acesso em: 16 nov. 2016.

SAVIANI, Dermeval. Neoprodutivismo e suas variantes: neoescolanovismo, neoconstrutivismo, neotecnicismo 
(1991-2001). In: SAVIANI, Dermeval. História das Ideias

Pedagógicas no Brasil. 3. ed. rev. Campinas: Autores

Associados, 2010. p. 425-440.

TODOS PELA EDUCAÇÃO. O TPE. Disponível em: http:// www.todospelaeducacao.org.br/quem-somos/quem-estaconosco/?tid_lang=1. Acesso em: 10 fev. 2017.

Recebido em: 5/5/2018.

Aprovado em 21/11/2018.

Publicado em: 8/11/2019.

Endereço para correspondência: Sonayra da Silva Medeiros Macêdo Av. Rio Branco, 1204 - Bela Vista 58428-860, Campina Grande, PB, Brasil

\section{Autoras:}

Sonayra da Silva Medeiros Macêdo

Doutoranda em Educação pela Universidade Federal da Paraíba (UFPB).

Orcid: https://orcid.org/0000-0002-3066-644X

E-mail: sonayramedeiros@hotmail.com

Maria Creusa de Araújo Borges

Doutora em Sociologia (UFPE). Professora Permanente do Programa de

Pós-Graduação em Ciências Jurídicas, área Direitos Humanos, e colaboradora do

Programa de Pós-Graduação em Educação, área de Políticas Educacionais,

da Universidade Federal da Paraíba.

Orcid: https://orcid.org/0000-0002-9982-1217

E-mail: mcaborges@gmail.com 